\title{
Why More Women Study Physics in Muslim Countries
}

\author{
Issues related to gender identity and the expression of femininity are key \\ to understanding the high representation of women in physics in Muslim \\ majority countries.
}

\author{
By Heba EL-Deghaidy
}

N omen are no good at physics, according to a prevalent myth. While the results of many studies counter that fiction (see Busting the "Men are Better at Physics" Myth), the idea persists [1, 2]. In many western countries, physics departments have a significant gender disparity, with far fewer women than men taking up the subject. But not all physics departments suffer from this problem. For example, in universities in countries where the majority of the population identifies as Muslim - so called Muslim-majority

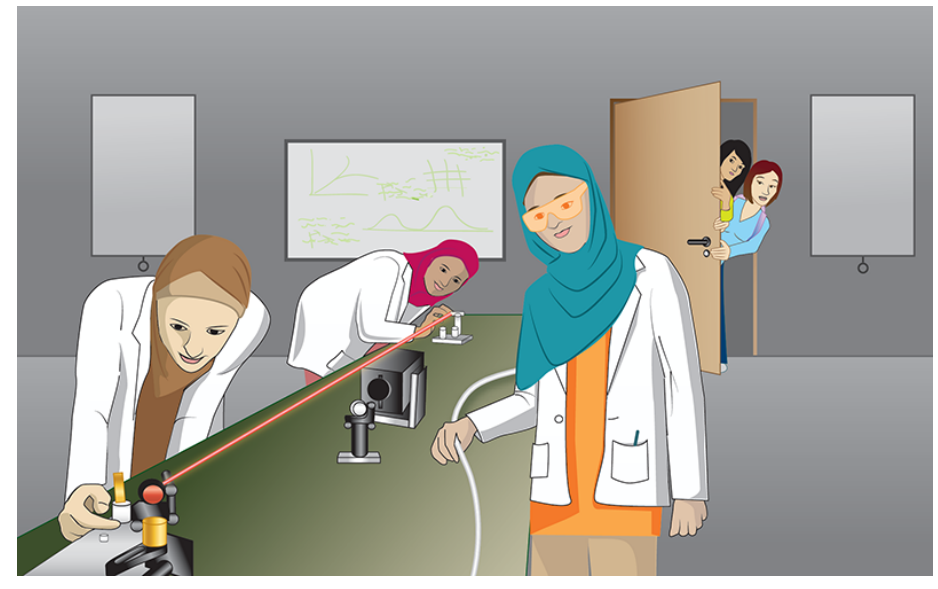

Figure 1: A new study identifies factors that draw women in Muslim-majority countries into physics. In these countries, women make up a much higher percentage of physicists that in western countries. The findings could help physics departments with a physics-gender-gap problem to broaden the participation of women.

Credit: APS /Carin Cain countries-women undergraduates often outnumber men. Now, Saaed Moshfeghyeganeh and Zahra Hazari of Florida International University uncover possible cultural reasons for this difference [3]. The findings could help countries with a physics-gender-gap problem broaden the participation of women, which is important for achieving gender equality in science and, more generally, for ensuring social justice and a strong economy [4].

Many groups have studied the physics-gender-gap problem, identifying a number of possible causes. For example, researchers have reported both subtle and blatant stereotyping of women in physics laboratories in the US, Canada, and Europe and have shown that such stereotyping negatively impacted women's careers [5] (see also Viewpoint: How Stereotypes Impact Women in Physics). That study and others all focused on western countries, where physics is a man-dominated field. For example, in the US, women make up $21 \%$ of undergraduates and $20 \%$ of Ph.D.s [6]. Not all parts of the world have such a man skew when it comes to science, however (Fig. 1). In Muslim-majority countries, such as Iran, for example, women make up more than $60 \%$ of students studying for physics undergraduate and master's degrees and $47 \%$ of Ph.D.s [7]. But until now, the possible roots of the higher prevalence of women scientists in these countries were poorly understood. The new study helps to fill in this knowledge gap by investigating the congruence of gender and physics identities in Muslim cultures.

In their study, Moshfeghyeganeh and Hazari interviewed seven women physicists aged between 30 and 60 years old. These women all studied physics in Muslim-majority countries and 
then moved to the US for academic positions. The women originated from Bangladesh, Iran, Jordan, Pakistan, Saudi Arabia, and Turkey-countries where over $95 \%$ of the population is Muslim. The duo asked the women questions about their lives from childhood through adulthood to find out why they had pursued physics and why they felt they had succeeded in making careers in the field. The interviews contained questions about what cultural expectations-from friends, family, and physics colleagues-these women felt.

The interviews highlighted five cultural areas where being a woman and being a physicist aligned. These areas were religion, social interactions, community goals, femininity, and family life. In Muslim-majority countries, social interactions with the opposite gender are less common and less encouraged than in Western countries. The seven women were mostly educated in gender-segregated classes. As a result, they did not feel out of place in a physics setting because of their gender. The women also noted that when they did interact with men physicists, they did not feel that they had to supress their femininity to have their intellect-and not their appearance-be the focus of the interaction. They put this down to their cultural norms of modest dress and modest adornment.

On family life, the interviews highlighted that the parents of all the study's participants strongly valued learning and had high expectations of their daughters when it came to education, a factor that the women said influenced their study and career choices. The women also noted no incongruence between practicing religion and working in science, two actions that can be at odds in other cultures. In Muslim cultures, physics is seen as a subject that serves societal goals, such as advancing technology or saving humanity, which align with religious goals.

Despite the high representation of women studying physics in Muslim-majority countries, it is worth noting that such countries do suffer from a "leaky pipeline" when it comes to employment [8]. The cultural expectations placed on women change dramatically after university, with their focus generally moving to personal and family responsibilities, rather than to employment.

Studies like this one by Moshfeghyeganeh and Hazari are important in identifying the factors that draw women to, and push them away from, physics. And the duo shows that when physics and gender identities align, women take up and successfully complete their physics education. There are also other ways to encourage women to study physics; for example, universities could design courses that focus on the societal relevance of physics; they could partner with companies that value diversity to provide internships for women students; and they could apply pedagogies that emphasize project-based learning. These changes could all help increase participation of women in physics, something that will be beneficial for many reasons. For instance, scientific teams made of people with diverse experiences and expertise tend to be more creative and innovative [9]. Scientists with different backgrounds also often ask different questions, which leads to unexpected insights that will only drive physics forward.

Find out more about the experience of women physicists in Muslim-majority countries in this Q\&A: Where Women Scientists Are the Majority.

Heba EL-Deghaidy: Department of International and Comparative Education, American University in Cairo, Cairo, Egypt

\section{REFERENCES}

1. E. Pollack, "Why Are There Still So Few Women in Science?" The New York Times Magazine (October, 2013).

2. B. Francis et al., "The construction of physics as a quintessentially masculine subject: Young people's perceptions of gender issues in access to physics," Sex Roles 76, 156 (2016).

3. S. Moshfeghyeganeh and Z. Hazari, "Effect of culture on women physicists' career choice: A comparison of Muslim majority countries and the West," Phys. Rev. Phys. Educ. Res. 17, 010114 (2021).

4. OECD, "Draft background note promoting gender equality in Eurasia: Better policies for women's economic empowerment" (OECD Eurasia Competitiveness Programme, 2019).

5. S. Thébaud and M. Charles, "Segregation, Stereotypes, and STEM," Soc. Sci. 7, 111 (2018).

6. A. Porter and R. Ivie, "Women in physics and astronomy, 2019," American Institute of Physics Report.

7. A. Iraji zad et al., "Improving the status of Iranian women in physics," AIP Conf. Proc. 1697 (2015).

8. S. I. Islam, "Arab women in science, technology, engineering and mathematics fields: The way forward," World J. Educ 7, 12 (2017). 
9. L. Smith-Doerr et al., "How diversity matters in the UD science and engineering workforce: A critical review considering integration in teams, fields, and organizational contexts," Engaging Science, Technology, and Society 3, 139 (2017). 